\title{
Los bibliotecarios y la formación de lectores
}

\author{
Héctor Guillermo Alfaro López *
}

Artículo recibido:

26 de marzo de 2009.

Artículo aceptado:

17 de noviembre de 2009.

\section{RESUMEN}

La biblioteca como formadora de lectores ha cobrado relevancia en los estudios bibliotecológicos, pero este supuesto presenta problemas de fondo sobre los que se reflexiona en este texto. Los bibliotecarios no son lectores y es sin embargo a ellos a quienes se les atribuye la misión de formar a los lectores, pero esa insuficiencia proviene desde su formación educativa como bibliotecólogos, la cual se enfoca el estudio de los documentos tomando en cuenta su valor de cambio y dejando de lado la parte correspondiente a su valor de uso, que es el que adquiere significación a partir de la lectura. Esto hace que en su ejercicio profesional dentro de la biblioteca, el bibliotecario se encuentre alienado de su objeto de

* Centro Universitario de Investigaciones Bibliotecológicas de la UNAM, México. galfaro@cuib.unam.mx

INVESTIGACIÓN BIBLIOTECOLÓGICA, Vol. 23, Núm. 49, septiembre/diciembre, 2009, México, ISSN: 0187-358X. pp. 179-195 
trabajo, que es el documento, y le impide comprender las necesidades de los usuarios como lectores. Contra esta tendencia se propone que el bibliotecario se asuma como lector para que pueda establecer una empatía lectora con los usuarios, lo que contribuiría a poner la biblioteca bajo el signo de un orden simbólico, lo cual complementaría y limitaría el orden técnico que en ella impera actualmente.

Palabras clave: Biblioteca; Formación de lectores; Valor de uso; Valor de cambio; Alienación; Empatía lectora; Orden técnico; Orden simbólico.

\section{ABSTRACT \\ Librarians and the formation of readers Héctor Guillermo Alfaro López}

The librarian as an educator of readers has lately taken relevance in library science studies, but such assumption has some main problems which are here reflected upon. Librarians are not lectors, but it is to them that the mission of forming lectors is attributed, an insufficiency due to his own education as library scientist who focus the study of documents considering its change value leaving aside its correspondent use value, which is what acquires signification in the act of reading. This turns the professional exercise of the librarian within the library in an alienation from his work object, the document, and inhibits his comprehension of the needs of users as readers. Countering this tendency, it is here proposed that the librarian assumes himself as a reader in order to be able to establish a reading empathy with users, and thus to contribute to put the library under the sign of the symbolic, which would complement and limit the technical order in which it actually operates.

Keywords: Libraries; Readers formation; Use value; Change value; Alienation; Reading empathy; Technical order; Symbolic order. 
T $\mathrm{n}$ aspecto de la lectura que gradualmente cobra mayor relevancia tanto para el campo bibliotecológico como para la sociedad en general es el papel que juega la biblioteca pública en la formación de lectores. Relevancia que incluso es puesta abiertamente de manifiesto y legitimada por la propia Federación Internacional de Asociaciones e Instituciones Bibliotecarias (IFLA), la que con la puesta en marcha del proyecto Encuesta Internacional de Lectura busca indagar y conformar un panorama sobre los servicios que las bibliotecas públicas ofrecen para la formación de lectores. Esto que por otra parte ratifica la representación que de la biblioteca pública, por sobre otras instituciones o instancias se hacen tanto los bibliotecarios como el público en general, de ser el pistón en la formación de lectores; tan firme es esta representación que adquiere categoría de axioma. Así, decir biblioteca implica concebirla necesariamente como institución formadora de lectores. Lo que redunda en una plusvalía para los bibliotecarios: el que popularmente se tenga la visión de ellos como lectores, incluso, como excelentes lectores. Pero la evidencia de tal axioma hace que se den por supuestas verdades que en el fondo encierran contradicciones, que así quedan soslayadas.

Al dar por supuesto que la biblioteca pública es el pistón de la formación de lectores se pasa por alto algo que puede parecer simple sino es que trivial decirlo: que la biblioteca no es un ente antropomórfico sino una institución dirigida por bibliotecarios, como diría Unamuno, de "carne y hueso". Todo lo cual viene a colación porque no es la biblioteca, que por sí misma sólo es un conjunto de instalaciones, la que puede llevar a cabo la formación de lectores, sino los bibliotecarios a cargo de ella. Son éstos quienes pueden hacer que la biblioteca deje de ser una entidad inerte y que sus instalaciones realicen las funciones para las que fueron estatuidas: valga la metáfora, ellos son quienes hacen de la biblioteca un organismo vivo. Pero atribuirle a la biblioteca per se la misión de formar lectores resulta un tanto impropio. Más bien tiene que especificarse que son las bibliotecarios quienes llevan a cabo las funciones propias de la biblioteca. Al subrayar esto se busca poner en el escenario a los actores que han de realizar la función particular de la formación de lectores.

Cuando se ubica en el primer plano a la biblioteca en la función de formar lectores, se deja de ver a quienes deberían emprender tal función, lo que redunda en que se den por sentado ciertos atributos que en realidad distan de cumplirse. Así queda como un supuesto del que no se hace mayor cuestionamiento, que los bibliotecarios por el simple hecho de serlo gozan del atributo de ser lectores consumados. Y si esto es así ¿quién mejor para formar lectores que los bibliotecarios? Y como es de esperarse el gremio se cobija con esa representación que socialmente se hace de ellos como lectores. Pero cabe preguntar si ese rol protagónico de los bibliotecarios como lectores se ajusta 
a la realidad. La autorizada palabra de Adolfo Rodríguez Gallardo nos dice al respecto:

Cuando se señala que el bibliotecario tiene que fomentar la lectura se está señalando una buena intención, y hablo de intención porque lo más trágico de este tema es que los bibliotecarios son pésimos lectores. Nadie puede enseñar lo que no práctica: cómo va un bibliotecario a promover la lectura si él mismo no es un lector. No lee ni libros ni periódicos. ${ }^{1}$

Las sumarias palabras supracitadas, hay que precisarlo, no son una mera opinión personal, subjetiva; muy por el contrario, están dichas con pleno conocimiento de causa. Los bibliotecarios no leen, por lo que no se les puede considerar lectores. En el mejor de los casos, para no cargar las tintas, podría decirse que los bibliotecarios entrarían en esa peculiar categoría que la socióloga francesa Joëlle Bahloul define como los "poco lectores": aquellos que leen pocos libros al año (de 1 a 4 ó de 5 a 9). ${ }^{2}$ Lo que es interesante señalar del modélico estudio sociológico de J. Bahloul es la fundamentada explicación que se da respecto a que cualquiera que sea el tipo de lector (no lector, poco lector, mediano lector o gran lector, tal es la clasificación de lectores que hace la socióloga francesa), éste se construye a partir de las trayectorias sociales que sigue a lo largo de su vida. Por tanto ser un lector o un no lector es un proceso que se construye y el cual puede variar o cambiar de trayectoria. No es, por tanto, un destino manifiesto predeterminado e inmutable ser o no lector, aunque en sociedades en las que se argumenta que hay escasos lectores pareciera que éstos son producto de un milagro. Pero si ser lector es producta de una construcción social entonces podemos decir, esperanzadamente, que aunque los bibliotecarios sean "poco lectores" esto puede cambiar y ellos pueden convertirse en grandes lectores. Pero esto no se realiza por decreto sino más bien por la conjunción de diversos factores, entre los que prioritariamente deben estar los que son propios de la formación bibliotecológica. Lo cual no descarta las excepciones de bibliotecarios que son grandes lectores o incluso lectores modelo. Pero como quiera que sea el hecho de que en la actualidad los bibliotecarios sean "poco lectores" plantea serios problemas que son los que ponen al descubierto la problemática que da sentido a la presente reflexión.

1 A. Rodríguez Gallardo, "Comentario", en Ramírez Leyva, Elsa M., (Coordinadora), La biblioteca pública y la formación de lectores en la sociedad de la información. Memoria, México, UNAM-CUIB, 2008, p. 182. 2002. 
La conseja popular estipula: se pregona con el ejemplo. Por lo que como subrayan las palabras de Adolfo Rodríguez: "cómo va un bibliotecario a promover la lectura si él mismo no es un lector", incluso si le damos a los bibliotecarios el estatuto de "poco lectores". Por lo que el axioma de la biblioteca como pistón en la formación de lectores queda en entredicho desde su propio fundamento. Lo que conduce a enunciar la problemática que atañe a esta reflexión: ¿por qué los bibliotecarios no son auténticos lectores siendo que el centro de su actividad son los impresos? ¿será que este problema se origina desde su propia formación como bibliotecarios, lo que estaría significando una insuficiencia en la educación bibliotecológica, que los incapacita para cumplir en la función de formación de lectores? y ¿qué acontece en la relación entre bibliotecario y usuario dentro del contexto de la biblioteca como mediadora de la lectura?

Como vía a la resolución de tales cuestiones señalo una hipótesis que en primera instancia puede sonar fuera de tono por no decir extravagante, que sin embargo tiene la virtud de explicar desde una perspectiva inédita (por sustentarse multidisciplinariamente) la complejidad de los procesos bibliotecarios: el bibliotecario se encuentra alienado de los documentos que son el centro de su actividad bibliotecaria. A la enunciación de semejante hipótesis hay que añadir que la mencionada alienación, consecuencia de considerar los documentos como mero objeto de trabajo, no se origina sólo de su actividad en la biblioteca sino que tiene su origen en la propia educación bibliotecológica que recibe el bibliotecario.

Por supuesto que resulta asombroso constatar que la mayoría de los bibliotecarios no son lectores o en su defecto son únicamente "poco lectores", ya que eso rompe no sólo con la representación que socialmente se hace de ellos, sino que va contra lo que puede considerarse la lógica de su profesión. Esa lógica hace inalienablemente equivalentes al bibliotecario con los impresos y, por lo tanto, con la lectura. Por el simple hecho de que los impresos son primero su objeto de conocimiento y después su objeto de trabajo, se espera que lógicamente los bibliotecarios se conviertan en consumados lectores. En casi todas las demás profesiones los libros, por especificar el más legitimado de los soportes de impresos, son sólo un instrumento que sirve para conocer los objetos particulares de tales profesiones, por lo que en esos casos la lectura es nada más un sucedáneo, no un objetivo en sí mismo. De ahí que no sea necesario para esos profesionistas ser lectores, basta que lean o que simplemente descodifiquen lo indispensable para su profesión. No tienen que hacer suyo el libro a través de la lectura. Pero en el caso de los bibliotecarios eso no aplica: por necesidad el bibliotecario debería llevar a cabo el apropiamiento de los documentos por mediación de la lectura, pero esto no sucede así debido a la alienación que tienen respecto a ellos. 
Alienación (o su variante: enajenación) es un concepto de larga tradición en filosofía, pero también tiene una amplia data en sociología y antropología. Su significado primario consiste en la "separación" que sufre el individuo (o la sociedad) respecto de sí mismo o en relación a la realidad externa en su diversa expresión: social, natural, material, etc., por lo que tiene principalmente una doble índole psicológica y sociológica. Como ya se adelantó, en el caso de los bibliotecarios, la alienación se manifiesta en la separación que sufre respecto a los documentos, debido a que los concibe como meros objetos de trabajo y, por lo tanto, como una entidad manipulable para ser entregada a otros, que serán quienes se los apropiarán por medio de la lectura. Pero tal alienación del bibliotecario en el ámbito laboral de la biblioteca sólo es el colofón de un proceso que se inició en su formación educativa bibliotecológica, cuando el documento era concebido como objeto de conocimiento. Para comprender ésta fase inicial de la alienación es preciso recurrir de manera análoga a un par de conceptos fundamentales de la economía: valor de cambio y valor de uso. Veamos primero su definición:

El valor de uso no constituye una cualidad intrínseca de una mercancía sino más bien su capacidad de satisfacer una necesidad humana. Para que una mercancía tenga valor de cambio debe poseer utilidad o, de un modo más estricto, debe ofrecer la promesa de utilidad para que pueda desearse y debe ser susceptible de intercambio. ${ }^{3}$

En síntesis el valor de uso satisface necesidades humanas, mientras que el valor de cambio consiste en la utilidad y se destina al intercambio. Toda mercancía tiene este doble valor, pero puede ocurrir que según los contextos, las situaciones o las actividades y orientación de los individuos se privilegie un tipo de valor sobre otro; lo que le abre la puerta a la alienación. Un libro, una revista o cualquier otro soporte impreso, así como los distintos soportes de imágenes no escapan a la ley de la mercancía. Por lo que se encuentran auroleados por el doble valor, privilegiándose uno u otro o los dos según se desenvuelvan en el proceso social de circulación de las mercancías. Al ingresar al campo bibliotecológico los diversos soportes de impresos o de imágenes salen del circuito de la circulación de las mercancías para insertarse en otro proceso de circulación, en el que su carácter precisamente de mercancías se transfigura cuantitativa y cualitativamente para convertirse en bien patrimonial de la sociedad. Así los mencionados soportes, al ser incorporados a las lor", p. 545. 
prácticas de la educación bibliotecológica y de la biblioteca, reconstituyen sus valores de uso y de cambio a partir de la lógica de tal campo; con lo que cambia el estatus de esos soportes para asumir la categoría de documentos, ${ }^{4}$ que en cuanto tales son un bien patrimonial social. El documento va a definir su propio valor de cambio y de uso una vez que sea reconfigurado por los procesos técnicos bibliotecológicos para estatuirse como registro (biblio) gráfico: ${ }^{5}$

Registro bibliográfico. Conjunto de datos formales que identifican y localizan un documento. Es una representación del documento resultado de la catalogación y por tanto un documento secundario. Está constituido por la referencia bibliográfica, los puntos de acceso y la signatura topográfica de cada documento. Su finalidad es facilitar su recuperación en un sistema de información y el acceso al documento original. Su confección está normalizada por las Reglas de Catalogación que incluyen la norma para la Descripción Bibliográfica Internacional Normalizada y las directrices de la IFLA para la normalización de los puntos de acceso o control de autoridades. La metodología consiste en crear un registro único para

4 "Documento. Información registrada sin que importe el soporte o las características. // Resultado de la fijación de la expresión simbólica de un mensaje sobre un campo de representación estable fuera del sistema cognitivo humano. J. López Yepes lo define como información fijada en un soporte físico transmisible en el espacio, en el tiempo y susceptible de constituirse en fuente de información para obtener nueva información. Según esta definición, existen dos partes bien diferenciadas en el concepto de información: a) el mensaje, es decir, un discurso expresado por un ente inteligente con una intencionalidad comunicativa y que se fundamenta en representaciones mentales o conocimientos sobre la realidad o mundos imaginados, y b) el campo de representación sobre el que se recodifica el mensaje, que tradicionalmente ha sido un objeto material (soporte) pero que actualmente puede ser una configuración energética. Teniendo en cuenta el carácter subsidiario del soporte, M. Pinto lo define como la acumulación permanente y estable de signos que puede ser explicada libremente, haciendo énfasis en las nuevas posibilidades que ofrece el mensaje documental frente al oral”. José López Yepes, (Editor) Diccionario Enciclopédico de Ciencias de la Documentación, España, Síntesis, 2004, Vol. 1, p. 471.

5 Debemos entender el concepto de registro gráfico de manera amplia, como aquél que subsume los documentos impresos o escritos así como los documentos de imágenes, como cualquier definición de diccionario estipula: (del lat. graphicus, y este del gr. graphikos; fr., graphique; i., diagram, graph, profile, chart, graphic chart, graphic, graphical; abrev., grâf.). Perteneciente o relativo a la escritura o a la imprenta. (DOCUMENTO GRÁFICO). 2. Que representa algo por medio del dibujo; diccionario gráfico. (DICCIONARIO POR LA IMAGEN; MATERIAL, PROYECTISTA GRÁFICO.) 3. Aplicase a las descripciones, operaciones y demostraciones que se representan por medio de figuras o signos. 4. Representación de datos numéricos por medio de una o varias líneas que hacen visible la relación que estos datos guardan entre sí. Martínez de Sousa, José, Diccionario de Bibliología y ciencias afines, España, Fundación Germán Sánchez Ruipérez, 1993 , p. 423. Por lo que en adelante se usará el concepto de registro gráfico. Esto por otra parte nos plantea el problema de la lectura de las imágenes, que también debería ser un componente de la educación bibliotecológica, dado el creciente auge y preponderancia de la imagen en las sociedades contemporáneas, además de que la presencia de las imágenes en sus diferentes soportes son ya parte infaltable en el acervo de las bibliotecas. Pero para no hacer más complicada la problemática aquí tratada sólo remito al libro: Alfaro López, H, G., Introducción a la lectura de la imagen, México, DGB-UNAM, 2009. 
cada documento que facilite el acceso a la información por cualquier dato de la descripción o de los puntos de acceso, e incluso por la signatura topográfica. ${ }^{6}$

El registro gráfico durante la formación educativa del bibliotecólogo, después bibliotecario, se convierte en objeto de conocimiento privilegiado. El proceso técnico que hace del documento un registro gráfico está dirigido por la concepción cognoscitiva de la ciencia, aunque desde una estrecha perspectiva positivista, lo que significa un empirismo pragmático que apela al desideratum objetivista científico. Semejante objetividad hace las veces de barrera contra las injerencias de la subjetividad; lo que produce que el estudiante de bibliotecología no se involucre con su objeto de conocimiento o, más exactamente, con su contenido. Por lo tanto su orientación cognoscitiva respecto al registro gráfico se da en términos de exterioridad que redundan en el no apropiamiento del documento: lo cual viene a ser la vía directa que conduce a la alienación laboral por lo que toca al objeto de trabajo del bibliotecario.

Así para el bibliotecario el registro gráfico pasa a ser el objeto de trabajo (como antes fue el objeto de conocimiento para el estudiante de bibliotecología), lo que también está significando que el proceso técnico que hace del documento un registro gráfico conlleve el privilegiamiento de su valor de cambio. Con ello se busca sustentar su dimensión utilitaria que lo predispone para el intercambio, de ahí que consista en el conjunto de datos que localizan e identifican un documento para facilitar su recuperación en un sistema de información y el acceso al documento original. Esta concepción del conocimiento y de la forma de elaboración técnica del registro gráfico va a determinar la formación del futuro bibliotecario y configurará así una mentalidad técnica ad hoc para la actividad que desarrollará en la biblioteca.

Darle prioridad al valor de cambio del documento le permite a la vez al bibliotecario ser un intermediario neutral entre la colección y el usuario; o, en otras palabras ser el verdadero gestor de la información que entrega para que le sea útil al usuario. Con esto queda establecido el servicio que le presta el bibliotecario de manera lineal y unidireccional al usuario, lo que implica que no hay posibilidad de retroalimentación: en la dirección que va del usuario al bibliotecario, los puentes de comunicación han quedado cegados. El bibliotecario es el poseedor de los conocimientos especializados propios de su profesión y eso le da la autoridad para suministrar y administrarle, los documentos al usuario, que por lo mismo asume una posición de receptor pasivo, subsidiario, mero consumidor de información. Quedan así claramente 
establecidos los roles y posiciones que guardan los actores en la biblioteca. De esta forma la biblioteca queda activada dentro de un orden técnico producto del privilegiamiento del valor de cambio del documento, donde prima el sentido utilitario. Ahora bien, todo esto no termina por explicar cómo se propicia la alienación del bibliotecario respecto al objeto que es el centro de su actividad. Esto sólo acabará por responderse con el problema que presenta el valor de uso del documento.

Recordemos que el valor de uso está destinado a satisfacer las necesidades humanas. Lo que nos plantea la cuestión de cómo se expresa el valor de uso en el documento. El valor de cambio instaurado por el registro gráfico estipula que la catalogación, en cuanto conjunto de datos que identifican y localizan un documento, tiene como finalidad facilitar el acceso a la información en él contenida, pero hasta ahí se queda la actividad cognoscitiva y práctica del bibliotecario. Utilizando una ilustrativa alegoría bíblica podría decirse que el bibliotecario a semejanza de Moisés conduce al pueblo elegido de los usuarios a la tierra prometida del registro gráfico, pero al igual que al profeta hebreo al bibliotecario no le fue concedido entrar a la tierra de promisión de la información que preexiste más allá del umbral de los datos catalográficos. Por esta razón el bibliotecario no alcanza a satisfacer sus necesidades humanas implícitas en el valor de uso del documento.

Hay que aclarar que el valor de uso del documento no consiste en la información en él contenida, ni tampoco en la simple descodificación de la misma, sino en su lectura. Lo que es pertinente subrayar es que la lectura no debe ser comprendida como una mera descodificación de un texto, puesto que es en realidad una práctica de extrema complejidad. La descodificación que hace el bibliotecario de los datos que le proporciona el documento es parte de la elaboración del registro gráfico, por lo que entra en el mismo proceso técnico que constituye el valor de cambio del documento. La lectura comprendida como un fenómeno complejo entraña las múltiples dimensiones que conforman al hombre y su mundo, de ahí que para estudiar la complejidad de esta práctica se requiera un enfoque integrador de sus múltiples aspectos como, por ejemplo, los enfoques lingüístico, psicolingüístico y sociocultural. ${ }^{7}$ Por medio de la lectura el lector se transfigura en las diversas esferas que lo configuran: intelectual, sentimental, sensorial y espiritualmente. Pero también la lectura conlleva estatuir una relación particular con el mundo y con los demás, relación mediada por los contenidos profundos de la textualidad, lo que significa el establecimiento de un espacio densamente simbólico que permea las relaciones entre el lector y el mundo. Todo esto le brinda un profundo 
sentido de lo humano al hombre y por eso la lectura de la información contenida en un documento le confiere su valor de uso. Esta es la tierra prometida que le ha sido vedada al bibliotecario, incluso desde la época de su formación educativa, más exactamente, es durante esa época cuando se le preparó para ser "poco lector". Porque sin que ése sea su cometido, así resulta, la educación bibliotecológica prepara al futuro bibliotecario para que sea "poco lector". ¿Cómo puede él ser formador de lectores si no fue formado como lector?

Como ya se indicó no se puede generalizar que todos los bibliotecarios no lean o sean poco lectores. Pero en el caso de la amplia mayoría de los bibliotecarios que son lectores esto se debió a su previa trayectoria social, como bien hubiera podido constatarlo la socióloga Joëlle Bahloul, y no como producto de una formación escolar orientada a tal fin. Los escasos bibliotecarios lectores lo son desde antes e, incluso a pesar de su formación bibliotecológica. Y aunque suene aún más paradójico, los bibliotecarios lectores lo son en contra de la educación que reciben puesto que la orientación técnica de la carrera que se avoca exclusivamente al valor de cambio del documento no fomenta la lectura. Lo que manifiesta el tratamiento oblicuo que se hace del objeto de conocimiento, en el que sólo se apela a la objetividad que distancia al documento del sujeto de conocimiento. Así el problema de la lectura ni siquiera es considerado o en el mejor de los casos actúa como un supuesto muy subrepticio, ya que se espera que el bibliotecario sea previamente un lector o en su defecto que algún día en la vida lo sea por la gracia de su libre albedrío.

Al no hacer hincapié a lo largo de la formación de los bibliotecarios en el valor de uso del documento por vía de la lectura, la educación bibliotecológica no permite su apropiación, lo que sólo provoca que quede obturado el acceso a su dimensión interna. El documento en cuanto objeto de conocimiento se convierte así en una entidad ajena que no permite su apropiamiento, por lo que la subjetividad del bibliotecólogo no alcanza a satisfacer las necesidades humanas que ofrece la lectura de los documentos. Esto adicionalmente contribuye a que no pueda desplegar el entorno simbólico que genera la lectura y que bien podría ser el contenedor y modulador de los excesos técnicos de valor de cambio que determinan la formación del bibliotecólogo.

Todo esto explica el porqué de los automatismos del bibliotecario en su función profesional, los cuales le otorgan una coloración unidimensional a su actividad dentro de la biblioteca; unidimensionalidad que es la negación de la complejidad. Al cerrarle al bibliotecario su propia educación bibliotecológica el acceso a la dimensión interna del documento por mediación de la lectura; esto es, al no haber sido formado como lector, este profesional se asume como mero gestor de la información y no como usuario también de la misma. Lo que deja de manifiesto la alienación que guarda respecto al documento, 
el cual es visto así como simple objeto de trabajo, exterior y ajeno, que en cuanto tal es un registro gráfico que es el que le ofrece al usuario para que penetre en su interior y se lo apropie a través de la lectura. La alienación respecto al objeto de trabajo causa que el proceso de separación se despliegue asimismo en las esferas psicológica y sociológica. La alienación a nivel psicológico se manifiesta en la distancia que se abre entre la asunción técnica de su profesión y el desconocimiento de los valores humanos que ésta tiene; y en el nivel sociológico en la separación respecto a los usuarios al establecerse entre ambos un muro invisible y diferenciador. De forma parcial quedan fijados así los roles de los agentes dentro de una biblioteca respecto al documento: el bibliotecario detentador de su valor de cambio y el usuario detentador de su valor de uso. Cuando cabría plantear, no necesariamente de manera utópica, la conjunción bidireccional de ambos extremos, lo que entrañaría el hecho de abrir la puerta de la biblioteca para que en ella circule la complejidad.

Veámoslo desde el ángulo hipotético: de haber recibido el bibliotecario una educación que le hubiera permitido el conocimiento igualitario y complementario del valor de uso y de cambio del documento de manera natural, él sería también un usuario de la colección de su biblioteca, el primer usuario de la misma y, por supuesto, de cualquier otra biblioteca del tipo que fuera. Pero además esto conllevaría la reconstitución de la dinámica bibliotecariousuario de forma compleja, lo que sería la base para que el bibliotecario hiciera de la biblioteca el pistón en la formación de lectores. Edgar Morin ha postulado los principios que ayudan a pensar la complejidad, que por lo mismo resultan pertinentes para establecer otra forma de relación entre bibliotecario y usuario por vía de la lectura: principio dialógico y principio de recursividad organizacional. Que son así enunciados por este pensador:

El principio diálogico nos permite mantener la dualidad en el seno de la unidad. Asocia dos términos a la vez complementarios y antagonistas. El segundo principio es el de recursividad organizacional. Para darle significado a este término, yo utilizo el proceso del remolino. Cada momento del remolino es producido y, al mismo tiempo, productor. Un proceso recursivo es aquél en el cual los productos y los efectos son, al mismo tiempo, causas y productores de aquello que los produce (...) Somos, a la vez, productos y productores. La idea recursiva es, entonces, una idea que rompe con la idea lineal de causa/efecto, de producto/productor, de estructura/superestructura, porque todo lo que es producido reentra sobre aquello que lo ha producido en un ciclo en sí mismo auto-constitutivo, auto-organizador, y auto-productor. ${ }^{8}$ 
A partir del principio dialógico se establece la dualidad en el seno de la unidad que es la biblioteca; así quedan asociados el bibliotecario y el usuario, que en cuanto tales son complementarios y antagonistas; el uno no es sin el otro. Con el principio de recursión organizacional se rompe con la linealidad del bibliotecario como exclusivo gestor de la información. Linealidad que establece que es él, como mediador entre la colección y el usuario, quien tiene el conocimiento especializado, y por ende la autoridad para ofrecer la información. Mientras que en el otro extremo de la línea el usuario es un mero receptor de la información. Por el contrario, recursivamente el bibliotecario y el usuario son al mismo tiempo, simultáneamente, causado y causante, producido y productor uno del otro y viceversa. El eje del movimiento recursivo en el espacio de la biblioteca entre usuario y bibliotecario es la lectura.

Continuando bajo el supuesto de que el bibliotecario sea un consumado lector, esto estaría implicando que es a la vez gestor y usuario de la información de la biblioteca. La conjunción de ambas funciones le permitiría sensibilizarse, comprender e interiorizarse en las necesidades de información del usuario y así satisfacerlas. Al recibir esa información el usuario a su vez se convertiría en gestor de la misma tanto hacia el exterior de la biblioteca, al proporcionársela a otros que están más allá de sus muros, así como al interior de ella al hacérsela extensiva al bibliotecario en nuevas demandas de información. Puede señalarse que mientras la función gestora de la información del bibliotecario es una actividad consciente por estar avalada por su formación especializada, la función equivalente del usuario es intuitiva y por lo mismo difusa. Cabría entonces añadirle a la tarea del bibliotecario la de contribuir a hacer consciente al usuario de su propia función gestora de información. Obvio, la clave sigue siendo la lectura. El usuario nunca es una tabula rasa, siempre es portador de un conocimiento que hace extensivo al bibliotecario bajo la forma de demanda de información, lo que el bibliotecario se convierta en usuario que tiene que estar actualizando su base informativa por medio de la lectura, para luego gestionar esa información. De esta forma uno y otro son causante y causado. Pero asimismo este proceso recursivo organizacional es productor y produce la empatía lectora entre bibliotecario y usuario. Empatía que hace que un lector comulgue con otro y se establezca así el profundo coloquio de los lectores, donde uno y otro se retroalimentan intelectual y vivencialmente con sus lecturas, llenando así ambos necesidades humanas de carácter social. Todo lo cual contribuye a que la lectura establezca entre los dos un espacio de intercambios simbólicos que acaba por cubrir el ámbito bibliotecario, con lo que éste se estatuye bajo un orden simbólico. La biblioteca como orden simbólico puede modular y humanizar a la biblioteca sustentada en un orden técnico, la cual es configurada así por bibliotecarios lectores (no 
alienados de su objeto de trabajo), los cuales ahora sí pueden ser legítimamente quienes pongan en marcha el pistón de la formación de lectores.

\section{Epílogo}

A lo largo de la exposición precedente queda de manifiesto un punto ciego en la educación bibliotecológica: la formación lectora de los bibliotecólogos. Auténtica asignatura pendiente que parcializa, segmenta y limita la formación de lectores que los bibliotecarios a su vez deberían llevar a cabo con los usuarios. Pero esto nos lleva consideraciones de fondo para explicar tal estado de cosas y con ello a vislumbrar alternativas.

Tanto por las necesidades que históricamente tuvo que satisfacer el campo bibliotecológico desde su origen hasta nuestros días, como por la tendencia contextual del mundo contemporáneo hacia una marcada tecnologización el resultado ha sido que la educación bibliotecológica estuviera signada por la orientación técnica. De ahí que resultara natural que se privilegiara el estudio del valor de cambio del documento, todo lo cual contribuyó a que la biblioteca cumpliera de forma eficiente y pragmática con las necesidades de información de las sociedades industriales en expansión. Esa misma eficiencia, no exenta de un fuerte lastre empírico, ha acabado por convertirse en un obstáculo epistemológico para el desenvolvimiento del campo bibliotecológico en su conjunto. ${ }^{9}$ Esta situación se ahonda debido a los acelerados cambios sociales que han propiciado el advenimiento de la sociedad de la información y la sociedad del conocimiento, por lo que para responder al reto que le ofrecen tales cambios el campo bibliotecológico tiene que reconstituirse desde sus fundamentos. La mera operatividad técnica es una frágil balsa ante la marea de la postmodernidad (o si se quiere de la hipermodernidad que pregona Gilles Lipovetsky). En particular la práctica de la educación bibliotecológica debe replantearse a fondo sus fundamentos, objetivos y orientación para preparar a los futuros bibliotecarios ante un mundo en vertiginosa transfiguración, lo que contribuirá ha hacer de la bibliotecología una ciencia fundada científicamente. Factor central para una reconstitución de la educación bibliotecológica es la cuestión conceptual, teórica y metodológica que les dé a los bibliotecólogos las herramientas, ya no sólo técnicas, para hacer frente de la forma más apropiada a los cambios en que estamos inmersos. Pero el basamento sobre el que se ha de apoyar la enseñanza de los elementos teóricos

9 Véase, H. G. Alfaro López, “La biblioteca como obstáculo bibliotecológico”, en Estudios epistemológicos de Bibliotecología, México, CUIB-UNAM, 2009. 
debe ser la lectura, por lo que no se puede postergar más la formación lectora de los bibliotecarios. Además siendo la vía real de acceso a la sociedad del conocimiento la lectura, no hay vereda ni atajo que valga (como lo es la mera descodificación funcional de un texto). El bibliotecario que mira de cara al futuro tiene que ser aquel que ha sido preparado para acceder al documento conjuntamente tanto por el escorzo del valor de cambio como por el escorzo del valor de uso, para no caer en la alienación.

Pero esto acaba por conducir al problema hacia el cómo instaurar en la educación bibliotecológica la formación de lectores. La bibliotecóloga colombiana Ruth Helena Vallejo Sierra en su texto "La lectura y los bibliotecólogos: encuentros y desencuentros" ofrece una opción, explica el plan que se llevó a cabo en la Universidad La Salle de su país, para que los estudiantes de bibliotecología se acercaran a la lectura.

El plan lector fue denominado "Canon de los 100 libros" en el que participó todo el cuerpo académico de la institución: "El plan lector propone la lectura de 20 libros generales y 80 disciplinares. Los 20 libros generales hacen referencia a la historia del humanismo y de la formación de las ideas, son una selección de literatura, filosofía, política, religión poesía y colombianidad. (...) La Facultad de Sistemas de Información y Documentación realizó la selección del Canon de los 80 libros, como propuesta en la cual se eligieron aquellos volúmenes considerados como los que todo bibliotecólogo y archivista debería leer; y diseñó una serie de estrategias de acompañamiento de lectura a la espera de que se generaran comportamientos lectores en sus estudiantes. Este proceso se inició durante 2006, y se puso en marcha en 2007. Se definieron entonces los objetivos para iniciar la construcción del Canon. ${ }^{10}$

Como el nombre del plan lo indica consiste en conformar de un canon de obras fundamentales para acercar a los estudiantes a la lectura. El diseño del canon fue acompañado de una serie de estrategias para que los estudiantes emprendieran la apropiación de los textos. Como confiesa la autora los resultados no fueron del todo alentadores:

Hemos aprendido también que la lectura disciplinar aunque es muy importante para la formación profesional, puede no ser el material más idóneo para generar comportamientos lectores. Tal vez la propuesta lectora que se planteó desde la facultad no fue el camino más adecuado para ello, pero es un intento. Será necesario 143-144. 
buscar muchas otras estrategias que logren un encuentro permanente del bibliotecólogo con la lectura. Por ello se escuchan todas aquellas propuestas que nos permitan encontrar espacio de encuentro para los lectores y la lectura. ¿Tendrán ustedes algunas propuestas? ${ }^{11}$

Como apostilla a estas descorazonadoras palabras muy bien puede decirse que "a la fuerza ni los zapatos entran" o, en otras palabras, que la lectura emprendida como consigna o por imposición termina por dar de bruces en el abandono o el repudio. Quizá este callejón sin salida al que llegó el plan del "Canon de los 100 libros" comenzó a perfilarse con el nombre mismo: canon, ya es sinónimo de autoridad. Y una obra que ha sido aureolada por el principio de autoridad suele despertar suspicacias si no es que rechazo abierto, principalmente cuando le es ofrecida a los jóvenes, que están en la edad de la impugnación y rebeldía. Tal vez un canon sea reconfortante y protector para los adultos, como lo son los profesores, pero no es del todo apropiado para un joven que comienza a caminar por la senda de la lectura.

Veamos ahora el problema desde otro ángulo: ¿qué tal si en vez de hacer sólo hincapié en la formación lectora de los estudiantes comenzamos por los profesores? La propuesta o la apuesta puede ser arriesgada si consideramos que en los profesores, los usos y costumbres profesionales están plenamente solidificados, por lo que puede resultar arduo emprender su formación lectora, pero es en ellos para quienes en primera instancia tienen que incidir las estrategias de encauzamiento a la lectura.

$\mathrm{Al}$ ser formados como lectores, los profesores estarán preparados para hacer de cada una de las asignaturas que imparten un escenario del despliegue de la lectura, que habrá de recorrer como un rumor los contenidos temáticos específicos de cada asignatura. Un lector avezado siempre encuentra los textos adecuados, aun si se trata de diversas áreas como literatura, filosofía, sociología, etc. para apoyar, ilustrar y enriquecer los contenidos de cualquier disciplina o asignatura, aunque sea la más eminentemente técnica. Lo que redunda en que a la par de darle un amplio horizonte cultural que enmarque la asignatura especifica en cuestión, le abrirá una senda que conduzca al universo de la lectura a los alumnos. De esta manera la lectura estará laborando dentro del aula, con lo que podrá en cada asignatura establecerse también el mencionado orden simbólico. Todo esto estaría implicando concebir la lectura como un proceso interno normal de la dinámica enseñanza-aprendizaje, no como un canon que irrumpe externamente nimbado de autoridad. Pero igualmente se estaría llevando a cabo a lo largo de la carrera universitaria de 
bibliotecología el conocimiento y asunción dialógica del valor de cambio y el valor de uso del documento. Así el círculo virtuoso de la formación de lectores de la bibliotecología quedaría sellado: profesores lectores que forman alumnos lectores que dan lugar a bibliotecarios lectores y que en cuanto tales forman usuarios lectores, los cuales a su vez retroalimentan a los bibliotecarios como lectores...

\section{BiBLIOGRAFÍA}

Alfaro López, H, G., Introducción a la lectura de la imagen, México, DGB-UNAM, 2009.

, Comprender y vivir la lectura, México, UNAM-DGB, 2007.

"El obstáculo epistemológico y la biblioteca", Memoria del

XXVI Coloquio de Investigación Biblitecológica y sobre la información, México, CUIB-UNAM, 2009.

"La lectura o los caminos de la comprensión y el poder", en Biblioteca Universitaria. Revista de la Dirección General de Bibliotecas de la UNAM, (en prensa). "La lectura como proceso de comprensión y conocimiento científico", en Investigación Bibliotecológica: archivonomía, bibliotecología e información, México, CUIB-UNAM, (en prensa).

"La biblioteca como espacio alienado de la lectura", en Memoria del XXVII Coloquio de Investigación Biblitecológica y sobre la información, México, CUIB-UNAM, (en prensa).

Bahloul, Joëlle, Lecturas precarias: estudio sociológico sobre los "poco lectores", México, FCE, 2002.

Bloom, Harold. Cómo leer y por qué, España: Anagrama, 2000.

Chartier, Anne-Marie, Enseñar a leer y escribir: una aproximación bistórica, México: Fondo de Cultura Económica, 2004, Espacios para la lectura.

Chartier, Roger, Las revoluciones de la cultura escrita: diálogo e intervenciones, Barcelona: Gedisa, 2000.

Cassany, Daniel, Tras las lineas: sobre la lectura contemporánea, Barcelona: Anagrama, 2006.

Ferreiro, Emilia, Cultura escrita y educación, $2^{a}$ ed. México: Fondo de Cultura Económica, 2000, Espacios para la lectura.

Jamet, Eric, Lectura y éxito escolar, Buenos Aires: Fondo de Cultura Económica, 2006, 123 p.

Lerner, Delia, Leer y escribir en la escuela: lo real, lo posible y lo necesario, México: Fondo de Cultura Económica, 2003, 193 p., Espacios para la lectura.

Littau, Karin, Teorías de la lectura, Libros, cuerpos y bibliomanía, Buenos Aires, Manantial, 2008.

López Yepes, José, (editor) Diccionario Enciclopédico de Ciencias de la Documentación, España, Síntesis, 2004, Vol. 1. 
Marina, José Antonio, De la Válgoma, María, La magia de leer, Barcelona, Plaza \& Janes, 2005.

Martínez de Sousa, José, Diccionario de Bibliología y ciencias afines, España, Fundación Germán Sánchez Ruipérez, 1993.

Morin, E., Introducción al pensamiento complejo, España, Gedisa, 1994.

Petit, Michèle, Lecturas: del espacio intimo al espacio público, México: Fondo de Cultura Económica, 2001, Espacios para la lectura.

Ramírez Leyva, Elsa Margarita, (compilador), Tercer Seminario Lectura: pasado, presente y futuro ¿Extinción o transfiguración del lector?, México, UNAM-CUIB, 2008.

Rodríguez Gallardo, A., "Comentario”, en Ramírez Leyva, Elsa M., (Coordinadora), La biblioteca pública y la formación de lectores en la sociedad de la información. Memoria, México, UNAM-CUIB, 2008, p. 182.

Seldon, Arthur y Pennance, F. G., (comp.) Diccionario de economía, España, Orbis, 1984.

Seminario Lectura: Pasado, Presente y Futuro (2003: México, D.F.), Lectura: pasado, presente y futuro: memoria del Seminario Lectura: Pasado, Presente y Futuro del 29 de septiembre al 2 de octubre de 2003, compiladora Elsa M. Ramírez Leyva. México: UNAM, Centro Universitario de Investigaciones Bibliotecológicas, 2005.

SMITH, Frank, Comprensión de la lectura: análisis psicolingüístico de la lectura y su aprendizaje, México: Trillas, 1985, 272 p.

Sociología de la lectura, Bernard Lahire, compilador, Barcelona: Gedisa, 2004. 